Check for updates

The BMJ

Cite this as: BMJ2020;370:m2918 http://dx.doi.org/10.1136/bmj.m2918 Published: 21 July 2020

\section{Covid-19: Shielding doctors express concerns about returning to work}

\section{Abi Rimmer}

Doctors who have been shielding during the covid-19 pandemic have said they are worried for their safety when they return to work.

From 1 August those who are at high risk of serious illness if they contract covid-19 will no longer be advised to shield in England, Scotland, and Northern Ireland.$^{1-3}$ But doctors who have been shielding during the pandemic have expressed concerns about their safety when they return to work, and say they feel forgotten by their employers.

Neurology registrar Mike Kemp conducted a small survey of shielding healthcare workers to gauge their views. He received responses from 100 healthcare workers, including 59 doctors. Over half (59\%) of the respondents said that they had not been risk assessed in preparation for their return to work. And almost three quarters $(70 \%)$ said they didn't know what measures would be in place to ensure their safety when they returned.

One anonymous respondent said, "I feel forgotten. I've done a huge amount of work from home to contribute to keeping outpatients running and feel my employer, training programme director, and NHS England have done nothing for me. I'm so worried about changeover and no one seems to have sorted anything despite it being in a few weeks."

Another said, "It is clear to me that the relaxation of lockdown is too early and unsafe, and that it is no safer for a high risk person to be out and about than it previously was. If I'm asked to return to face-to-face I will have to choose between my career and my health, and I will be forced to choose my health."

Kemp, who is shielding by proxy, stressed that he has been well supported and provided with work to undertake while he is shielding to further his training, but said this was not the case for everyone.

One doctor who responded to the survey said that there had been limited information from any of the medical royal colleges about the impact that shielding would have on training and flexibility in rotations. "It's been disappointing to say the least."

The BMA has published a briefing document on supporting staff who are shielding to return to work. It says that employers should provide evidence of the safety measures that are being put in place to make workplaces "covid-19 safe" to reassure staff who are returning to work. ${ }^{4}$

Kemp said that it became clear to him through discussions with other shielded healthcare workers that this group felt under-supported.

"We are now at a point where shielding doctors feel at the most risk, when stepping back towards some semblance of normality, we need to ensure they are safe to do so but also that they feel safe in doing so," Kemp said. "This survey demonstrates this feeling across the shielded healthcare workforce and that a great deal more needs to be done to support them."

\footnotetext{
Public Health England. Guidance on shielding and protecting people who are clinically extremely vulnerable from covid-19. 14 July 2020. www.gov.uk/government/publications/guidance-on-shielding-and-protecting-extremely-vulnerable-persons-from-covid-19/guidance-on-shielding-and-protecting-extremely-vulnerable-persons-from-covid-19\#what-will-change-from-1-august.

Scottish Government. Coronavirus: if you need to shield. 16 July 2020. www.mygov.scot/coronavirus-if-you-need-to-stay-at-home.

3 NI Direct. Coronavirus (covid-19): pausing of shielding for extremely vulnerable people. 2020. www.nidirect.gov.uk/articles/coronavirus-covid-19-pausingshielding-extremely-vulnerable-people.

4 BMA. Briefing on supporting staff who are shielding to return to work. July 2020. www.bma.org.uk/media/2854/bma-briefing-on-supporting-return-to-workjuly2020.pdf.
} 